\title{
Embedded Present Tense and Attitude Reports
}

\author{
Silvia Gennari \\ Brown University
}

\section{Introduction}

When indexical tenses such as present tense occur in intensional domains, there is a mismatch between the actual content of the propositional attitude and the attitude reported. Consider for example:

(1) John believed that Mary is pregnant.

(2) John will believe that Mary is pregnant.

Here, the temporal interpretation of the embedded state may overlap with the believing time and the speech time (ST) (the double access reading, Abusch 1991, 1997). But, intuitively, John's beliefs do not include the ST, i.e., a future or past time from John's perspective. In (1), for example, John presumably had a belief about Mary's pregnancy at a past interval (overlapping with the time of his belief) and not necessarily at an interval extending into his future to include the ST. This holds for (2) as well relative to the past. In both cases, the temporal reference to the ST does not coincide with the temporal belief the believer seems to have.

Current solutions to this problem propose that there is a de re interpretation of the embedded tense, parallel to those found with regular NPs. In this paper, I argue that this solution is not entirely satisfactory because the de re interpretation does not make the correct predictions for cases in which the double access reading and the content-report mismatch obtain but the interpretation has the properties found in de dicto interpretations. As an alternative, I propose that reports containing indexical tenses involve an attribution of an implicit attitude similar to those traditionally acknowledged in the philosophical literature. I argue that such attributions are felicitous if there is an inference attainable in the common ground that allows the speaker to infer and assert the attributed content. The inference involves the hypothetically explicit content attributed to the attitude holder and pragmatic premises normally taken for granted. This account correctly predicts whether a given report is felicitous on the basis of the availability of the speaker's inference.

\section{Previous solution}

The most extensive solutions proposed in the literature for present under past sentences are those in Abusch $(1991,1997)$ and Ogihara (1996). They propose that embedded indexical tenses are interpreted $d e r e$, in a way parallel to de re interpretations of noun phrases. The embedded tense, rather than being part of the intentional content of the attitude holder, is the speaker's way to refer to the entity the belief is about. In the attitude worlds, this entity may be represented differently.

The particular analysis of $d e$ re readings adopted from the nominal domain is that of Cresswell and Stechow (1982). The analysis involves a res, i.e., a thing or entity toward which the attitude is held. The object of belief is a structured meaning or centered worlds, a pair consisting of an individual and a property $\langle b, P\rangle$, where $b$ is the res of which the property $P$ is predicated. The account also assumes following Kaplan (1968) and Lewis (1979) that the res is presented to the 
believer in a certain way via a causal connection. This is captured by postulating that there is a suitable cognitive relation $R$ presupposed in the context between the believer and the res in the actual world. With these tools, Cresswell and Stechow define the truth conditions for de re belief reports: $a$ believes $P$ of $b$ iff $a$ bears some suitable relation $R$ to $b$ in the actual world $w$ and every doxastic alternative $w^{\prime}$ of $a$ satisfies the property of bearing $R$ uniquely to something which has $P$ in $w^{\prime}$.

To understand the intuition behind this definition, consider Quine's famous example of Ralph's beliefs. Ralph glimpsed a guy wearing a brown hat in the beach, who we identify as Ortcutt, and thinks that the guy is a spy. In this scenario, one can report Ralph's beliefs as Ralph believes that Ortcutt is a spy, where Ortcutt is interpreted de re given that Ralph does not represent the guy as Ortcutt. In this case, the acquaintance relation is a relation $R$ such as $x$ glimpses $y$ in the beach. Then, Ralph believes Ortcutt to be a spy iff Ralph bears some acquaintance relation $R$ to Ortcutt in the actual world and every doxastic alternative of Ralph is such that Ralph bears the relation $R$ uniquely to someone who is a spy. This analysis thus captures the fact that there are different modes of presentation associated with the individual Ortcutt. The content of the acquaintance relation gives us the way Ralph represents the individual (the guy seen in the beach), while Ortcutt is the way the speaker refers to him.

To apply this analysis to the temporal domain, the object of which an individual has a belief must be a temporal entity such as an interval or state. Consider the case of (1) repeated below:

John believed that Mary is pregnant.

John may have seen Mary once and thought she was pregnant, although she may have actually been overeating. In this scenario, John is acquainted with the state or interval of Mary's having a big belly, and he believes of this interval to be such that Mary is pregnant in it. Abusch represents this acquaintance relation as follows:

$\mathrm{R}_{3}: \lambda \mathrm{t}_{\text {now }} \lambda \mathrm{x} \lambda \mathrm{t} \lambda \mathrm{w}$ [t is the maximal interval overlapping with $t_{\text {now }}$ at which Mary has a big belly in $w]$

$R_{3}$ is a relation between the res interval $t$ and the individual $x$ in $w$ at $t_{\text {now }}$, the time of the attitude or the believer's now. It picks out the maximal interval overlapping with the believer's now at which Mary has a big belly. As in Cresswell and Stechow's proposal, the truth conditions are given in terms of the acquaintance relation and the property assigned to the res interval. The property $P$ assigned to the interval is of type $\langle i,\langle i,\langle w, t\rangle\rangle\rangle$ (property of times) and is the property of being an interval such that Mary is pregnant in it. As before, the definition of belief says that (1) is true iff (a) there is a relation $R$ that causally connects the res interval $t$ with John at the time of believing $t_{\text {now }}$ in the actual world $w$ and (b) for all John's cognitive alternatives, the interval $t$ to which John is acquainted in his belief worlds has the property of being the interval of Mary's pregnancy.

Note however, that these truth conditions do not yield the double access reading of the embedded present tense. As they stand, they only guarantee via the causal connection $R_{3}$ that the interval picked out by $R$ overlaps with the believing time (i.e., with $t_{\text {now }}$ in (3)). Since both Abusch's and Ogihara's accounts assume that present tense lexically refers to the ST (or to a non-past time), extra assumptions are needed to ensure that the interval referred to by the present tense is also the interval picked out by $R$ which overlaps with the believing time.

In Abusch's system, the double access reading is accomplished by stipulating two temporal constraints on the denotation of temporal expressions. To 
understand how these constraints work, first note that the embedded present tense moves to a higher position in LF in order to be interpreted de re. The resulting representation is the following (where the text at the nodes represents the corresponding type of the category):

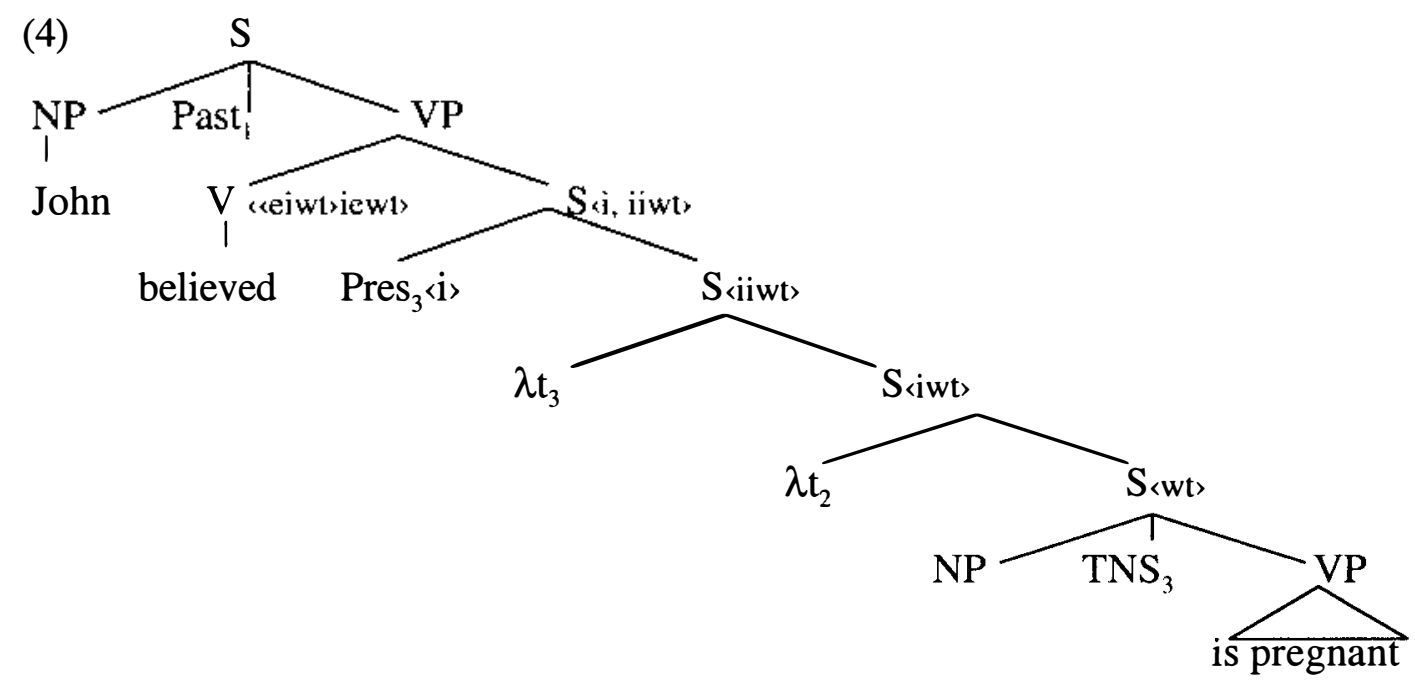

In (4), the present tense Pres $_{3}$ overlaps with its evaluation time, the ST, rather than with the evaluation time of the base position $t_{2}$. Note that Abusch requires evaluation time abstractors for each of the temporal arguments within the embedded clause. She suggests that these times are counterparts in the belief worlds of the actual times denoted by the tenses. $t_{2}$, the believer's now, is the counterpart in the belief worlds of Past $_{l}$, the actual believing time. It represents the evaluation time of the embedded sentence. The trace $\mathrm{TNS}_{3}$ is the counterpart in the belief worlds of Pres $_{3}$ that overlaps with the ST. $\lambda t_{3}$, then, is the temporal property abstracted over the trace $\mathrm{TNS}_{3}$, i.e., the property of being a time such as that when evaluated relative to $t_{2}$, Mary is pregnant in it.

The proposed temporal constraints impose restrictions on both actual and believed (counterpart) times. First, the Upper Limit Constraint prevents $\mathrm{TNS}_{3}$ from referring to a time later than its local evaluation time $t_{2}$. This constraint stipulates that forward reference of tenses in intensional contexts is impossible because future times are not sufficiently determined from the perspective of the now of the attitude holder. The evaluation time is thus an upper limit for the denotation of embedded tenses. Second, the actual and the belief worlds are required to be isomorphic (I will call this the isomorphism constraint). That is, when the reference of Pres $_{3}$ overlaps with the believing time Past ${ }_{1}$ in the actual world, the reference of $\mathrm{TNS}_{3}$ overlaps with the believer's now in the belief worlds. With these two constraints, several logical possibilities regarding temporal readings are eliminated. For example, $\mathrm{TNS}_{3}$ cannot follow the believer's now in the belief worlds because it cannot refer to a future time (the Upper Limit Constraint). In turn, it cannot precede the believer's now because it must be isomorphic with the ST, which does not precede the believing time in the actual world. By the same isomorphism constraint, since $\mathrm{TNS}_{3}$ can thus only overlap with the believer's now, the reference of Pres $_{3}$ should also do so. The possibility that is left is the double access reading graphically represented in (5), where the slashes indicate the references of Pres $_{3}$ and $\mathrm{TNS}_{3}$ in their respective world: 


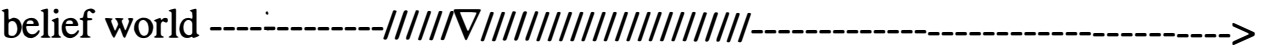

$$
\begin{aligned}
& \text { believer's now } t_{2} \\
& \text { actual world --------|/IIII/ } \\
& \text { believing time } \text { Past }_{1} \quad \text { ST }
\end{aligned}
$$

The reference of Pres $_{3}$ overlaps with the believing time and the ST in the base world while $\mathrm{TNS}_{3}$, the counterpart of Pres $_{3}$, overlaps with the believer's now in the belief worlds. Although the present tense only overlaps with the ST according to (4), the temporal constraints guarantee that it also overlaps with the believing time. Thus, the double access reading is obtained.

Note that, from the truth conditions above and these temporal constraints, it does not follow that at the belief worlds, Mary is pregnant at the ST. In these worlds, she has to be pregnant at the interval with which John is acquainted via $R_{3}$, i.e., the interval at which the symptoms persist. This interval in the belief worlds is independent from the ST and only overlaps with the believer's now. However, the interval reference of the de re constituent in the actual world is such that it overlaps with the believing time and the ST. This is because the acquaintance relation picks out the reference of the res constituent in the actual world and the constraints on temporal relations lead to the double access interpretation in this world. The acquaintance relation thus picks out two different intervals in each world. Pragmatically, according to Abusch, these conditions amount to a presupposition that Mary's symptoms overlap with both the believing and the utterance time. The res interval is what the speaker is taking for granted. Since this condition has to hold in the actual world for the sentence to be appropriate, the double access effect is achieved. Thus, the meaning of tenses, the de re analysis, the Upper Limit and isomorphism constraints give the right semantics for present under past reports.

Consider now how the double access reading is achieved in Ogihara's proposal. Ogihara proposes a de re analysis about states and requires in the truth conditions that the state in question obtains at the ST. Also, the analysis provides a mechanism to rule out occurrences of indexical tenses within intensional domains. This is accomplished by postulating two different principles that amount to a ban on the occurrence of indexical expressions within intensional domains. A consequence of these principles is that the embedded present tense should obligatorily move out of the intensional domain to the COMP level of the matrix sentence. The final representation at LF and the truth conditions are the following (taken from Ogihara 1996):

$$
\begin{aligned}
& \text { a. LF: }\left[\operatorname{CPres}_{2}\left[{ }_{s} \text { John Past believe } s_{2}\left[{ }_{\mathrm{CP} 1} \text { that }\left[\mathrm{s}_{\mathrm{s}} \text { Mary } \mathrm{s}_{1} \text { be pregnant }\right]\right]\right]\right] \\
& \text { b. } \exists \mathrm{s}_{2}\left[\operatorname{exist}^{\prime}\left(\mathrm{st}, \mathrm{s}_{2}\right) \& \exists \mathrm{t}\left[\mathrm{t}<\mathrm{st} \& \text { believe' }\left(\mathrm{t}, \mathrm{j}, \mathrm{s}_{2}, \lambda \mathrm{t}_{3} \lambda \mathrm{s}_{1}\left[\text { be-preg' }\left(\mathrm{s}_{1}, \mathrm{~m}\right)\right]\right)\right]\right]^{1}
\end{aligned}
$$

$s$ is a state and exist is an "operator" such that $[$ exist $]](s)(t)=1$ iff $t$ is included in the duration of $s$. According to the proposed truth conditions for de re attitude verbs, (1b) is true iff there is a state $s_{2}$ at the ST such that John in the past ascribes to $s_{2}$ the property of being a state of Mary's being pregnant. More precisely, the sentence is true iff (a) there is a state $s_{2}$ at the ST and an acquaintance relation $R$ that relates John uniquely to this state $s_{2}$ in $w$ at the believing time $t$, and (b) for all doxastic alternatives $\left\langle w^{\prime}, t^{\prime}, x^{\prime}\right\rangle$ of John in $w$ at $t$, John bears the relation $R$ in $w^{\prime}$ at $t^{\prime}$ uniquely to some state, which is the state of Mary's being pregnant in $w^{\prime}$ at $t^{\prime}$. The double access reading is captured because the truth conditions require that (a) the attitude holder and the res state are acquainted at the time of the attitude $t$, i.e., 
the res state overlaps with the believing time $t$, and, (b) the res state exists at the ST. By definition, the res state thus overlaps with both the ST and the believing time.

\section{Problems with the de re analysis}

There are two main problems that challenge the de re account. The first one concerns its failure to explain all reports containing embedded indexical tenses. Note that both Abusch's and Ogihara's de re accounts rely on two pragmatic conditions imposed on the actual world. One is the truth requirement that there be an acquaintance relation that picks out some relevant state in the actual world, although not necessarily the state denoted by the complement sentence. The other is the truth requirement or constraint that the state to which the believer is acquainted also obtains at the ST. If these conditions do not obtain, the double access reading and the content-report mismatch would not be explained. For example, in (1), if Mary does not have a big belly at the ST, the interval picked out by the acquaintance relation in the actual world would not be an interval overlapping with both the believing time and the ST. In such a case, the attribution would be considered infelicitous or false.

There are, however, examples in which one or both of these conditions are not met, although the double access reading and/or the content-report mismatch still obtain. Consider the following. Imagine a situation in which Mary intentionally wanted to appear fat in order to deceive her boyfriend John. She wants him to marry her and she believes a pregnancy would force the issue. She has used a pillow under her shirt on several occasions. Her boyfriend is now in a business trip and Mary is of course not fat any more, as in fact, she never was. In this context, it is perfectly fine to utter (6):

John believed that Mary is pregnant and that he'll have to marry her.

Here, John is only acquainted with Mary's pillow state in the past. The condition that the state with which the believer is acquainted obtains in the actual world at the ST does not hold. Consider also the following case:

Betty told little Bill the Santa Claus is preparing his gift.

In (7), the attitude holder does not have to be acquainted with any actual state that overlaps with both the attitude time and the ST, as the de re account requires. In both situations (6) and (7), the reports would be predicted false or infelicitous and both the content-report mismatch and the double access reading would not be explained ${ }^{2}$. following:

Similar considerations arise for the case of generic beliefs. Consider the

(8) Socrates believed that the soul is located in the stomach.

(9) Scientists believed that the human mind starts to develop long after birth.

(10) Skinner denied that the mind exists.

As in (6), the most natural interpretation of these sentences suggests that the existence of a state or interval overlapping with both the ST and the believing time in the actual world is not required. Similarly, there does not seem to be an acquaintance relation between the believer and some actual state or interval that, as in the Ortcutt case, gives us the believer's representation of the state. Socrates may have believed the complement of (8) as a statement compatible with his system of 
beliefs, without being acquainted with any particular state that also obtains at the ST. Rather, as in (7), the state or interval in question may only exist de dicto in the belief worlds, challenging the adequacy of the de re analysis.

There are, however, two possible objections to this reasoning. In defense of the de re account, one could argue that these cases involve some sort of actual generic state with which the believer is acquainted. For example, one could imagine that Socrates in (8) was acquainted with the state of humans behaving the way they do and he believed of this state to be the state of the soul being located in the stomach. However, the question arises as to what the acquaintance relation really is and how it is constrained. Note that it is normally the case that believers have de dicto or de re beliefs because their mental states are causally connected to their experience (Stalnaker 1984). If I believe that the table is brown, normally, it is because the table is brown, or because I believe something that entails this proposition. The vagueness inherent in the notion of acquaintance relation thus makes the de re account able to explain virtually any belief, hence the relatively unusual example mentioned in (7). It will normally be the case that the believer is ultimately connected to some state in the actual world. Unless further constraints are specified, the acquaintance relation is not sufficient to explain those beliefs for which the existence of a related res state is not easily identifiable.

The other objection in defense of the de re account is to say that the present tense involved in generic sentences is not the same present tense (or the same use of the tense) as that of double access sentences. However, there is no a priori reason to assume this. In fact, there are reasons that suggest that such an assumption is not correct. First, generic sentences are no restricted to present sentences so that their particular interpretation does not come from the present tense. Second, the genericity of sentences such as (8)-(10) is usually taken to come from a generic operator (cf. Carlson and Pelletier, 1995) and not from the use of a different present tense. Also, the problems posed by these sentences are similar to those of (6) and (7), which are not generic sentences. Given this, I prefer to assume that the meaning of the present tense is one and the same in all occurrences and that an appropriate unifying account would explain all cases. Thus, the two possible objections to the problem of belief reports, if taken seriously, in fact reveal other problematic assumptions and potential difficulties implicit in the de re analysis.

The second main problem that challenges the $d e$ re account concerns its failure to account for double access readings in which there is no content-report mismatch involved. Note that there are relative clauses in which the double access reading obtains but the characteristics of de re attitudes are not present:

John met the guy who lives downstairs.

John hired an engineer who has two graduate degrees.

In (11) the interval of living overlaps the past meeting time and the ST. The de dicto/de re distinction (or Quine's opaque vs. transparent notion) is relevant only when intensional domains are involved. But (11) and (12) contain no such domains. There is no content-report mismatch or de re attribution that would justify the adoption of the de re analysis as presently formulated. For these examples, Abusch and Ogihara's theories assume that QR may apply, moving the object NP to the CP. Regardless of whether QR applies or the object NP stays in situ, the analyses yield a temporal reading of the present tense that overlaps with the ST, due to the lexical meaning of the tense. Thus, the double access reading is not explained ${ }^{3}$.

In sum, there are examples in which the requirements of the de re analysis and the characteristics of de re readings are not met. This shows that this analysis does not systematically explain the double access reading and/or the content-report 
mismatch. The de re mechanism either misanalyzes these cases or leaves them unexplained. This thus casts doubts on the empirical adequacy of generally adopting a de re analysis to explain the content-report mismatch and the double access reading of cases such as (1) and (2).

\section{Alternative solution}

Given the problems of the de re accounts, I maintain that the content-report mismatch of sentences such as (1) and (2) occurs because the reports of these sentences are reports of implicit or tacit attitudes, i.e., the content reported differs from that explicitly believed but follows from it, given the addition of certain pragmatic assumptions. Also, I argue that the double access reading directly follows from the appropriate semantic definition of the present tense and is somewhat independent of the problem of the content-report mismatch. The mismatch occurs because of the characteristics of the speaker's act of attribution; the double access reading occurs because of the semantics of the tenses involved. The speaker chooses to report an implicit attitude that happens to be conveyed by the semantics of the present tense. The choice of the present tense thus correlates with the report of an implicit attitude but such reports are not restricted to double access readings.

\subsection{The double access reading}

To start with, consider how the temporal reading and the truth conditions of present under past reports are obtained. The crucial assumption to obtain the correct interpretation is the definition of the meaning of present tense. In my dissertation, I analyze the behavior of the present tense in both independent and embedded contexts and propose a semantic definition that account for its interpretations in all environments: The meaning of present requires the proposition it modifies (a) to overlap with the local evaluation time and (b) not to be located before the ST. Formally, its meaning is $\lambda i \exists i^{\prime}\left[i^{\prime} o i \&-\left(i^{\prime}<s t\right) \& \varphi\left(i^{\prime}\right)\right]$, where $o$ means overlap with, $i$ is the evaluation time and $i$ ' the interval at which $\varphi$ is true. The motivation to propose this meaning is that present tense has a non-past perspective and could be true at a future interval if embedded under future (as in (2)), i.e., the present tense can denote any non-past interval overlapping with the local evaluation time without necessarily referring to the ST (for a discussion, see Gennari 1999). This meaning agrees in spirit with several proposals (Kamp \& Reyle 1993 and Abusch 1997) in which the temporal perspective of present is considered to be non-past. Also, Abusch (1988) proposes a definition of present tense where the interval denoted overlaps with both the evaluation time and the ST. The novelty of this definition is that the references to the ST and to the evaluation time are put together in a way that is particularly suited to account for embedded sentences.

For the case of present under past reports such as that of (1), the result of the semantic composition is as follows:

John believed that Mary is pregnant.

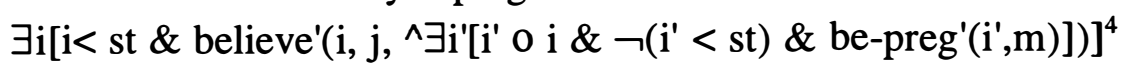

This says that (1) is true iff there is an interval $i$ prior to the ST at which for all of John's belief worlds, there is an interval $i$ ' such that (a) it overlaps with $i$, John's believing time, (b) it is not an interval before the ST, and (c) Mary is pregnant at it. Note that by definition of the before and after relations, $-\left(i^{\prime}<s t\right)$ means that $i^{\prime}$ is not 
wholly located before the ST. Thus, an interval $i^{\prime}$ that overlaps with the past believing interval $i$ and is not wholly located before the ST, necessarily requires that $i$ ' overlaps with both the past believing interval $i$ and the ST. The resulting situation is depicted in (13), where the slashes represent the interval denoted by the present tense. A similar result obtains for the case of relative clauses such as (11) and (12), in which the interval denoted by the present tense overlaps with the time of the past main verb ${ }^{5}$.

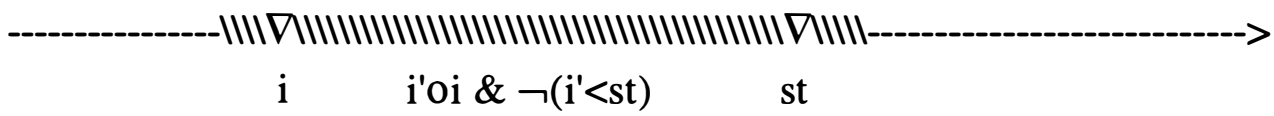

The truth conditions thus yield an interpretation of (1) in which it follows from what John believed at $i$, that Mary is pregnant during an interval overlapping with the believing time $i$ and the ST. However, these truth conditions also seem to commit the believer to a belief about an interval overlapping with a future time, the ST from the perspective of the speaker. To address this issue, I argue here that such a commitment need not be assumed if the speaker's report is viewed as a report of an implicit attitude, rather than an explicit one representing John's literal belief. A content inferred by the speaker with the aid of common sense assumptions is not necessarily part of what the believer actually had in mind.

\subsection{The content-report mismatch}

In (1), John did not actually have a belief about an interval extending into the future from his past perspective, but his belief entailed that the embedded state was true in the past and would be true in the future, given the speaker's addition of pragmatic assumptions normally taken for granted. The speaker attributes to John typical assumptions and knowledge of the world from which the implicit content reported logically follows. If John believed at a time before the ST that Mary was pregnant, the speaker could infer that John believed that she was pregnant and would be pregnant for a while, given that John has rational beliefs and normal knowledge about pregnancy. Before uttering the sentence in (1), the speaker goes through an inference schematically represented as follows:

(14) (a) John believed that Mary was pregnant at $t$.

(b) John's belief worlds are coherent.

(c) John believed that Mary had a normal pregnancy.

(d) John knew that pregnancies typically last for an interval $i$ including $t$.

(e) $i$ includes a future time $t^{\prime}$ (the ST from the speaker's perspective).

$\rightarrow$ John believed that Mary is pregnant at $i$ including $t$ and $t^{\prime}$.

From the speaker's perspective, the future time $t^{\prime}$ in John's worlds is the ST. Note that this account requires that the embedded interval denoted by the present tense in (1) exists in the belief worlds, rather than in the actual world. The inference that Mary's pregnancy obtains at a future time $t^{\prime}$ holds in the belief worlds. Moreover, the actual belief may only be about a past interval (premise (a)). The speaker's pragmatic inference concludes the pregnancy at the ST implicit in John's beliefs, given normal assumptions and typical knowledge. The notion of implicit report, traditionally acknowledged (cf. Stalnaker 1984), is further constrained here by the existence of a pragmatic inference, the premises of which (if any) should be taken for granted in the common ground. In particular, I propose that an implicit report such as that in (1) is felicitous, if there is an inference attainable in the common 
ground that allows the speaker to infer the attributed content. This is because, by the very nature of implicit attitudes, the speaker cannot assume any proposition as part of the belief worlds. Rather, he/she may assume those propositions that are normally taken for granted, i.e., those that constitute common knowledge and default assumptions. This is the crucial difference that distinguishes report of implicit attitude from de re reports.

Note that premise (c) of (14) schematically represents other premises also implicitly assumed by the speaker. For example, John did not think at the time of the belief that Mary was about to give birth, or John did not have any reason to think that Mary would not have a normal and full term pregnancy. These are part of normal assumptions that the speaker takes for granted in the common ground and thus attributes to the believer. This correctly predicts that if the speaker knew that John thought that Mary's situation was somewhat atypical (for example, that Mary was sick and could loose the child), the present under past report would be infelicitous.

Two pieces of evidence support this account. First, the pragmatic assumptions of (14) are independently motivated on other pragmatic assumptions that interlocutors normally assume when making and interpreting attitude reports. As several studies have pointed out (cf. Stalnaker (1984), Barwise and Perry (1983), Mc Cawley (1978), Farkas (1992)), when the speaker makes an attitude report, he/she normally assumes that (a) attitude holders are rational beings, i.e., belief worlds tend to be coherent (I call this assumption the normality principle); and (b) that the belief worlds agree with the actual world (or with the version of the actual world that the speaker presupposes) in all relevant respects except for those in which the speaker has given the hearer reasons to believe that they may differ (equal knowledge principle). These assumptions are clearly operative in (14). Since the believer is rational (premise (b)), has typical knowledge about the world and makes normal assumptions about Mary's situation as presupposed in the utterance context (premises (c) and (d)), the speaker can infer that the believer's worlds are such that they entail the persistence of certain state.

The second piece of evidence supporting this account comes from the existence of implicit reports other than those involving a temporal inference. The philosophical literature about attitudes has pointed out the need for such a notion to account for reports that intuitively seem neither literal belief report nor de re (cf. Stalnaker 1984). Consider for example, the following:

Russell believed that Frege's ear lobe was smaller than The Big Ben. President Clinton said that the country is doing well.

In (15), Russell presumably did not have this explicit belief but it follows from the general pragmatic knowledge attributed to him by the speaker. The attribution of a belief may take for granted beliefs of which the believer is not aware. In (16), uttered in a situation in which Clinton has given his two hour State of the Union speech, the president actually did not utter the complement but it was implied by his speech and everything his speech presupposed. Attributions thus do not necessarily represent explicit contents because they can be made on the basis of an inference whose premises are attainable in the common ground ${ }^{6}$.

Thus, this account only requires the standard semantic analysis of beliefreports, while the speaker is responsible for the use of the present tense with its corresponding semantic interpretation via his/her own pragmatic inference. What creates the intuition that the speaker misrepresents the original belief is the inference process the speaker goes through in the report, which in most cases, attributes a stronger belief than the original content, given the premises added to the belief worlds. 


\section{Predictions}

\subsection{Non-existent and discontinuous states}

The approach proposed in the previous section can predict why examples presupposing discontinuous states in the actual world are not acceptable. These examples have been used in the literature to support the claim that the state with which the believer is acquainted should obtain in the actual world at an interval overlapping with the believing time and the ST. Consider for example, a case slightly different from one given by Ogihara:

(17) John and Bill are looking into a room. Sue is in the room.

John (nearsighted): Look! Mary is standing in the room.

Bill: What are you talking about? That's Sue, not Mary.

On the following day, Bill and Kent return to the same location and are now looking into the same room. Sue is standing there.

Bill (to Kent): \# John believed yesterday that Mary is standing in the room. But that's Sue not Mary.

The attitude report in (17) is infelicitous. This is because under normal assumptions, an inference such as that in (14) applied to this case would not normally follow. Consider how the inference would be formulated:

(a) John believed that Mary was in the room at $t$.

(b) John's belief worlds are coherent.

(c) John believed that Mary was in a typical state of being in the room.

(d) John knew that a state such as being in a room typically lasts for an interval $i$ including $t$.

(e) ${ }^{*} i$ includes a future time $t^{\prime}$ (the ST from the speaker's perspective).

$\rightarrow *$ John believed that Mary is in the room at $i$ including $t$ and $t^{\prime}$.

To obtain the reported content the speaker should assume that the state in question would typically hold in the belief worlds for a period $i$ that includes the ST (premise (d)). However, this assumption does not hold because it contradicts common sense knowledge about the duration of the state. John likely believed that Sue would stand there for a while but not until next day. Temporary states such as that of standing in a room cannot be typically assumed to hold for long periods. Neither the speaker nor the believer would normally take this for granted.

This type of pragmatic reasoning also makes the right predictions for cases in which no actual state obtains at the ST. According to the equal knowledge principle, such attributions should make available in the context that the believer does not have access to the same information the speaker presupposes. This is the case of (6), where Mary deceives her boyfriend:

(6) John believed that Mary is pregnant and that he'll have to marry her.

In the context provided, the speaker knows that Mary was never pregnant but can assume that she was and would be in the belief worlds since John was deceived. Likewise for Socrates' example (8), since given what we know about him, such a generic belief would follow from his past beliefs regardless of what happens at the ST in the actual world. Note, however, that these examples do not violate common 
sense assumptions about the duration of states as in (18). The reported belief is compatible with common sense assumptions and what is presupposed in the common ground so that the report can be felicitous, although no state may obtain at the ST in the actual world. Thus, the examples of this section show that the felicity of a present under past report depends on whether a pragmatic inference can be constructed according to what is normally taken for granted in the common ground. If what the speaker assumes in the belief worlds is incompatible with the presupposed context, the inference is not available.

\subsection{The generic/episodic contrast}

If it is correct that the speaker makes an inference that assumes common knowledge about the typical duration of states, one would expect variations in the acceptability of present under past reports depending on the degree of reliability of such an assumption. This is an issue particularly for those embedded states that may not hold between the time of the attitude and the ST as exemplified in (18). If common knowledge does not support the inference, the report should be unacceptable. In contrast, if no issue arises as to whether the embedded state can hold for the period specified, the sentence should be fine. This is indeed what we find. Note that among the stative sentences that can occur embedded under past, there are at least two classes corresponding to the distinctions between generic vs. episodic sentences (Carlson 1977, Kratzer 1988, Cherchia, 1995). At the level of lexical stative verbs, this distinction corresponds to the distinction between individual level and stage level predicates. Sentences containing individual level predicates and generic sentences in general express permanent or typically stable properties. In contrast, sentences containing stage level predicates express temporary qualities or states.

It should become clear now why the generic/non-generic distinction has an effect on the acceptability of present under past attributions. This is so because temporary states (stage level predicates) will yield awkward sentences if they are asserted to hold for periods that are longer than what one would normally expect according to world knowledge. Consider for example:

(19) ??Last year, John believed/told me that Mary is pregnant.

(20) ??Last week, the dean told me that Ms. Jones is sad.

(21) ?Last month, the secretary told the dean that Ms. Jones is upset with him.

Compare these sentences with the following:

(8) Socrates believed that the soul is located in the stomach.

(9) Scientists believed that human psychology starts to develop after birth.

(22) I used to believe that dogs and cats love each other.

(23) Last week, the dean told me that Ms. Jones is walking/walks to school.

Generic sentences (both habitual and with individual level predicates) are fine no matter how long ago the attitude took place. They do not require specific conditions to be acceptable when embedded under past because the original generic belief contained quantification over typical situations (the sentence is habitually true), and therefore, it logically entails that the embedded sentence is true for a period encompassing the believing time and the ST. The presence of the inference is pragmatically unquestionable and does not require extra common sense assumptions. In contrast, temporary states hold for periods that are grounded in typical knowledge so they are most likely to yield infelicitous present under past sentences if common sense assumptions are not satisfied (as in (18)). The less 
likely the assumption, the less felicitous the sentence, hence the various degrees of acceptability. In general, the presence of an inference more or less pragmatically grounded (including logical inferences as those unquestionably grounded) determines the felicity of present under past reports.

\subsection{Other pragmatic factors}

Consider a situation such as that in (1) in which Mary was pregnant, had the baby and got pregnant again. John saw Mary a month ago but he does not know anything about Mary's present state or Mary's having the baby. In this situation, the report in (1), John believed that Mary is pregnant, is infelicitous. The de re account handles this case via the requirement that the state obtaining in the actual world overlaps with both the ST and the believing time. In my account, no state is required to exist in the actual world but John still has a belief about one state rather than two, since the meaning of the present tense forces the embedded proposition to be true throughout the interval overlapping with the believing time and the ST. However, since the context makes explicit that John's worlds continued to be the same since he saw Mary and the interval intervening between the believing time and the ST does not violate normal assumptions about pregnancies, it is therefore possible to infer the conclusion of a present under past report. This case would be like those cases discussed earlier in which no actual state obtains at the ST.

Note however that there are other pragmatic reasons to rule out reports such as (1) in the context described. In a situation where the speaker knows that there were two pregnancies involved, it would be simply uncooperative to utter (1), since the speakers does not provide all the information that is relevant for the situation. This is also true for the past version of (1). For the speaker to be informative, he/she must report John's belief in a way that clearly characterizes John's beliefs against what is presupposed in the speaker's context. In the context given, the speaker actually means something like (24):

John thought that Mary is/was still pregnant from the first pregnancy ${ }^{7}$.

Therefore, using (1) or its past version would be misleading, since it does not make clear to the hearer what John actually has in mind, given the actual situation.

In terms of Stalnaker's (1978) theory of assertion, the asserted report does not satisfy the conditions for a felicitous assertion: The speaker does not distinguish between the possible worlds of the current common ground, thus making the proposition false in some worlds and true in others. An assertion that is true in all (relevant) worlds of the common ground is infelicitous. For example, (1) does not distinguish between a belief about the first or the second pregnancy. According to Heim (1992), a belief report such as (1) instructs one to exclude from the common ground those worlds in which John does not believe that Mary is pregnant. But since in this case, John can have such a belief regarding one of the two states (e.g. John does not believe that Mary was pregnant for the second time), the speaker's contribution is not clear and the assertion is not felicitous. This captures Gricean informativeness principle in a precise way: the assertion was not informative enough relative to the current common ground. Thus, the contrast between (24) and (1) in the context provided suggests that in addition to the common sense assumptions discussed above, other general pragmatic principles such as Gricean cooperation and informativeness principles may determine the acceptability of present under past reports. 


\section{Some puzzles on acceptability: the present attitude}

The acceptability of present under past belief reports seems to be affected by the beliefs the believer holds at the ST. If it is known in the common ground that the belief that was held in the past is no longer held at the ST, the present under past attribution is not felicitous. This is a problem for all accounts, since the explanations rely on the belief the believer had in the past (or the state the believer was acquainted with at a past time). Interestingly, this contrasts with verbal attitudes such as those introduced by say, tell, announce, etc.. In such cases, whether the attitude holder still holds an attitude at the ST is irrelevant for the felicity of the report. Consider the following:

(25) John and Bill are looking into a room. Sue is in the room.

John (nearsighted): Look! Mary is in the room.

Bill: What are you talking about? That's Sue, not Mary.

John: Yes, your are right. That's Mary.

One minute later, Kent joins them. Bill (to Kent):

a. John said that Mary is in the room.

b. \# John believed that Mary is in the room.

(26) John knows that Mary lives in California now.

a. \# However, for a while, he believed that Mary lives in Boston and expected to call her up to go out together.

b. However, last week, he said that Mary lives in Boston and made everybody believe so.

(27) John believed that Mary lives in Boston and expected to call her up to go out

together. However, he found out yesterday that she lives in California.

If the possibility that the believer changed his mind is available in the common ground, belief attributions, as opposed verbal ones, are not acceptable. However, the order of presentation in the discourse yields a difference in acceptability, since (27) is fine. Facts of this nature support my pragmatic account, since the information available in the common ground at the time of the attribution has an effect on felicity. The contrast between verbal and cognitive attitudes, however, is a puzzling fact for which I do not have a definitive answer, although I will suggest a possible explanation rooted in the meaning of these attitudes.

Attitudes such as belief, as opposed to knowledge, are subject to revision. Note that even if I am sure that yesterday I believed that the secretary was and would be pregnant today, after I found out that I was wrong, I cannot report my past belief today with embedded present tense. This would be so even if I can attribute to myself all the necessary premises for the inference or, on terms of the de $r$ account, even if the state I was acquainted with still obtains (e.g., the secretary was not pregnant but just fat). Belief worlds are stable and tend to be coherent. New evidence causes re-interpretations of past beliefs. Given this, one could argue that reports attributing implicit beliefs are also implicitly subject to a ceteris paribus condition: the speaker's inference is valid all other things being equal, i.e., it is taken for granted that the believer does not have access to new evidence that proves the belief wrong. In such a case, a revision of the content would take place and from the perspective of the ST, the past belief would not entail any more that the state in question persists at the ST.

This contrasts with reports of verbal attitudes. Such reports introduce the set of worlds that the attitude holder presupposed in the original speech act, rather than belief worlds. These worlds may but need not be stable, and do not commit the attitude holder with the truth of his/her statement or a certain view of the world. So, they are not subject to revisions and no ceteris paribus condition is necessary. Even 
if the attitude holder now knows that his/her past speech is false, this does not undermine his/her present or past verbal acts.

Note that under this view, the ceteris paribus condition constitutes an implicit premise of the speaker's inference. Thus, it is subject to the same kind of pragmatic constraints we have indicated for other premises. The condition will hold, as long as the common ground does not contradict it. This explains why (27) is fine. At the point the attribution is made, the ceteris paribus condition can be assumed in the inference, since the common ground does not presuppose that a revision took place. Therefore, no conflict arises. This contrasts with (25.a) and (26.a), where the common ground denies the condition.

\section{Present under future}

Present under future sentences in their double access reading have similar characteristics to present under past ones. Consider, for example:

The dean will say that Ms. Jones is his wife. $\exists i\left[i>s t \&\right.$ say'(i, j, ^ヨi' [i' o i \& $\neg\left(i^{\prime}<\right.$ st) \& be-wife'(i', m)])] The dean will believe that John's records are not good enough. $\exists \mathrm{i}[\mathrm{i}>\mathrm{st} \&$ believe'(i,the-dean', ^ヨi' [i'oi \& ᄀ(i'<st) \& ᄀbe-good'(i', john's-records')])]

Note that by the above definition of the present tense, the two temporal readings in these sentences are obtained. The condition of not being an interval prior to the ST can be satisfied in different ways. For example, (28) is true in two possible situations: when Mary is John's wife at some future interval overlapping with John's saying time and when Mary is currently John's wife and continues to be until John's saying time. In the first case, the event time of the present complement $i^{\prime}$ is a future interval overlapping with the future local evaluation time. In the other case, this interval is extended enough to overlap with the ST and the future local evaluation time. Whether the embedded interval overlaps with the ST will be determined by the context.

As in the case of present under past, when the double access reading obtains, the speaker attributes an implicit future attitude based on an inference including common sense assumptions. The speaker attributes an attitude that will be such that, given normal assumptions, it will entail something true about the past of the attitude time (the ST), although the attitude holder may not know this at the ST. The difference with present under past reports is that what is entailed by the belief worlds looks backward instead of forward, i.e., once the believer acquires certain knowledge, his/her view of the past will change. For example, in (29), the dean will believe that John's records are bad at a future time $t$. But, since the dean will learn that John's records are generally bad at an interval $i$ including $t$, and since $i$ includes $t-1$ (the ST), it follows that the dean will believe that John's records are bad at an interval including $t-1$. (28) behaves similarly, except that here, since a verbal attitude is involved, the dean will not necessarily acquire a new belief, as (29) suggests, but could say what he/she already knows.

This analysis is supported by facts similar to those found with present under past reports regarding the continuity and actuality of the states involved. Assuming a context such as that in (6) where Mary is about to deceive her boyf riend with a pillow, the future under past report need not require the currency of the state in question at the ST: 
John will think that Mary is pregnant.

Humans will never know whether there is life on other galaxies.

At a future time, John will think that Mary was and has been pregnant, given the characteristics of this state, although no state may obtain at the ST. In addition, a state obtaining at the actual world is not required as (31) shows. Thus, the inferential approach correctly accounts for these cases.

Present under future reports are also similar to present under past ones with respect to the contrast observed between generic and episodic complements. Generic complements are usually fine independently of the time intervening between the ST and the future attribution, while the felicity of temporary states with the double access reading depends on whether the assumption that the complement state holds for the indicated period is pragmatically attainable:

Next year, the dean will believe that John is sad.

Next year, the dean will believe that the secretary is pregnant.

The dean will believe that Ms. Jones is not trustworthy.

The students will think that Socrates is the greatest philosopher of all times.

In the double access reading, the speaker should infer from normal pragmatic assumptions that the complement state would remain true from the attribution time backward to the ST, unless he/she has given reasons to suspend them. If such assumptions are unattainable in the common ground as in (32) and (33), for the same kinds of pragmatic reasons indicated for present under past, the double access reading will not arise. Thus, these brief considerations and the parallelisms noted with present under past attributions suggest that the general approach proposed for present under past sentences extends to the case of present under future.

\section{Conclusions}

In this paper, I have argued that the adoption of a de re analysis to account for indexical tenses within intensional domains does not make the correct predictions. In contrast, I have proposed an alternative account, which relies on a definition of the present tense and the fact that attitude reports can attribute implicit contents. This notion is important because it provides an alternative view to account for reports that do not intuitively seem $d e$ re. Reports of implicit attitudes are such that their felicity is conditioned to the existence of an inference pragmatically attainable. Although more study is needed to determine the general adequacy of this notion, the solution proposed for the temporal cases analyzed here requires the standard possible worlds semantics of attitudes and a pragmatic theory of attitude reports that constrains the speaker's inferential attribution. In contrast with current accounts, the proposal is simple and relies on principles and notions motivated by independent facts of the grammar. The approach also simplifies the syntax-semantics interface and correctly predicts the felicity of the reports under consideration.

\section{Endnotes}

(*) I am in debt to Craige Roberts for conversations that inspired this article and to Pauline Jacobson for innumerable comments that improved it.

1 It is not clear to me why $\lambda t_{3}$ does not bind any variable in the embedded proposition. This is the representation given in Ogihara (1996), p. 212-14. 
${ }^{2}$ Note that it does not matter that in (7), Betty lies to little Bill. From the perspective of the speaker, the attribution could be true.

${ }^{3}$ A further potential problem for the de re account are multiply embedded present sentences. Consider the following:

(a) Mary suspected that her father thinks that he has cancer.

In these cases, the innermost interval/state denoted need not be analyzed $d e$ re. The analyses would require that there is an acquaintance relation in the actual world that connects the father in (a) to some actual state. However, Mary could be mistaken about her father's beliefs and misrepresent his mental state. In such case, the de re account predicts that the attribution in (a) would be false or infelicitous, although it does not have to be so. It should be noted, however, that Abusch's and Ogihara's accounts do not actually discuss multiply embedded cases. So, some other mechanism could be brought in to deal with them. Ogihara, for example, proposes an optional tense deletion rule that applies to embedded tenses given their identity with the matrix tense. If the rule deletes the tense, the embedded sentence is interpreted as overlapping the immediately higher tense. However, since the tense deletion rule is optional, it is not clear what happens when the rule does not apply.

${ }^{4}$ Note that the semantic representation given for (1) admits the occurrence of indexicals within the intensional domain. This is something that the de re accounts have banned by means of different ad hoc constraints. The motivation for this, according to Ogihara, is that the believer does not have "access" to the ST. This sort of constraints forces the movement of the present tense outside the intensional domain. My take on this problem is that the occurrence of indexical tenses within intensional domains is not problematic if one assumes a theory of attitudes such as that of Stalnaker $(1981,1987,1990)$. This theory challenges the assumptions of $d e$ re accounts such as those proposed by Lewis (1979) and Cresswell and Stechow (1982). In contrast with the structured meaning approach, Stalnaker's framework assumes that the object of an attitude is simply an abstract proposition, which could be denoted by several different sentences. The occurrence of an indexical expression in a complement sentence does not mean that the believer has access to the ST. It only means that the propositional content of the belief is a function of the time denoted by the present tense, but this proposition is independent from the indexical means by which the time is specified. In (1), for example, John does not have a belief about the ST, but an (implicit) belief about an interval that includes the time denoted by "st", not the expression "st" itself. As Kaplan (1989) and Numberg (1993) have pointed out, the deictic component of indexical expressions is not part of the proposition expressed. Indexicals are the speaker's handy means to express the abstract proposition object of the attitude.

${ }^{5}$ The representation of a relative clause such as that of $(11)$ is the following:

John met the guy who lives downstairs.

$\exists i\left[i<s t \& \exists x\left[g^{\prime} y^{\prime}(i, x) \& m^{\prime} e^{\prime}(i, j, x) \& \exists i^{\prime}\left[i^{\prime}\right.\right.\right.$ oi \& $\neg\left(i^{\prime}<s t\right) \&$ live'(i',x, downstairs')]]

This gives a reading in which the interval of living overlaps with the meeting time. There also is another possible reading obtained by the application of QR. In this case, the present tense is outside the scope of the main past tense, yielding a purely present reading, as in the following example: 
(11') John met the guy who is (now) coming up the stairs.

$\lambda t\left[\exists \mathrm{i}^{\prime}\left[\mathrm{i}^{\prime} \mathrm{o} t \& \neg\left(\mathrm{i}^{\prime}<\mathrm{st}\right) \& \exists \mathrm{x}\right.\right.$ [guy(i',x) coming-up' (i',x) \& $\exists \mathrm{i}[\mathrm{i}<\mathrm{st} \&$

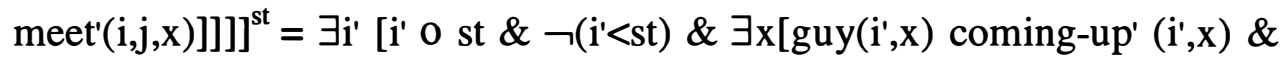
$\left.\left.\exists \mathrm{i}\left[\mathrm{i}<\mathrm{st} \& \operatorname{meet}^{\prime}\left(\mathrm{i}^{\prime}, \mathrm{j}, \mathrm{x}\right)\right]\right]\right]$

In this case, the evaluation time of the present tense is the ST, as in any independent sentence. The two available readings of the present tense occurring within relative clauses are thus accounted for.

${ }^{6}$ Note that the notion of implicit attitude advocated here is not the one implied by the traditional possible worlds approach to attitude reports. The kind of implicitness claimed here is conditioned to the existence of an inference on the basis of what would normally be taken for granted. To see this, compare this notion with the problem of equivalent beliefs. If $a$ believes that Phosphorus is Phosphorus, in the traditional propositional account, $a$ must also believe that Phosphorus is Hesperus, since the two propositions are necessarily true. The traditional account may argue that in a weak sense of belief as implicit belief, such inference may hold. Although there are theories of attitudes such as that proposed by Stalnaker $(1984,1987)$ that handle this puzzle within the possible world framework, this kind of inference would not follow from my notion of implicit attitude since it would not be normally assumed that anybody has complete knowledge of either astronomy or all the sentences that express the same proposition.

${ }^{7}$ The present version of this sentence was accepted by at least 6 speakers prompted with the relevant context. However, Some speakers do not accept it, even though they agree that it is better than (1).

\section{References}

Abusch, D. 1988. "Sequence of tense, Intensionality and scope", in Proceedings of the Seventh West Coast Conference in Formal Linguistics, Standford: CSLI Publications.

Abusch, D. 1991. "The Present under Past as De Re Interpretation", in Proceedings of the Tenth West Coast Conference on Formal Linguistics, Stanford, CSLI Publications.

Abusch, D. 1997. "Sequence of tense and temporal De Re", $L \& P, 20,1-50$.

Barwise, J. \& Perry, J. 1983. Situations and attitudes, MIT Press, Cambridge, Massachusetts.

Carlson, G. 1977. Reference to Kinds in English, Ph.D. dissertation. University of Massachusetts, Amherst. Published in 1980 by Garland Press, NY.

Carlson, G. \& Pelletier, F. 1995. The Generic Book, University of Chicago Press. Chicago.

Chierchia, G. 1995. "Individual-Level Predicates as Inherent Generics", in Carlson, G. \& Pelletier, F. The Generic Book, University of Chicago Press. Chicago, p. 176-223.

Cresswell, J. \& Stechow, A. (1982) “De re belief Generalized”, L\& P, 5, pp. 503535.

Farkas, D. 1992. "Two types of world-creating predicates", in Brentari et al. (eds.), The Joy of Grammar, John Benjamins, pp. 35-71.

Gennari, S. 1999. Tense meanings and temporal interpretation, Ph.D. dissertation. Brown University. 
Heim, I. 1992. "Presupposition Projection and the semantics of attitude verbs", Journal of Semantics, 9, pp. 183-221.

Kamp, H. \& Reyle, U. 1993. From Discourse to Logic: Introduction to Model theoretic Semantics of Natural Language, Formal Logic and Discourse Representation Theory, Dordrecht: Reidel.

Kaplan, D. 1968. "Quantifying in", Syntheses, XIX, 178-214.

Kaplan, D. 1989. "Demonstratives", in Almog, Perry and Wettstein (eds.) Themes from Kaplan, New York: Oxford University Press, pp. 481-563.

Kratzer, A. 1989. "Stage-Level and Individual-Level Predicates", in Paper on Quantification, GLSA, University of Massachusetts, Amherst, p. 147-222.

Lewis, D. 1979. "Attitudes De Dicto and De Se", Philosophical Review, LXXXVIII, No. 4. 513-543.

Mc Cawley J. 1978. "World creating predicates" in VS 19/20, p. 77-93.

Numberg, G. 1993. "Indexicality and deixis", $L \& P, 16$, pp. 1-44.

Ogihara, T. 1996. Tense, Attitudes and Scope, Kluwer, Reidel, Dordrecht.

Soames, S. 1989 "Direct Reference and Propositional attitudes", in Almog, Perry and Wettstein (eds.) Themes from Kaplan, New York: Oxford University Press, pp. 393-419.

Stalnaker, R. 1978. "Assertion" in Cole (ed.) Syntax and Semantics 9, New York: Academic Press, pp. 315-332.

Stalnaker, R. 1981. "Indexical belief" in Synthese, 49, pp. 129-151.

Stalnaker, R. 1984. Inquiry, MIT Press, Cambridge, MA.

Stalnaker, R. 1987. "Semantics for Belief" in Philosophical Topics, Vol. XV, No. 1, Spring, pp. 177-190.

Stalnaker, R. 1990. "Mental content and linguistic form" in Philosophical Studies, 58, pp. 129-146. 